\title{
Prevalence of chronic kidney disease stages 3-5 among patients with type 2 diabetes mellitus in Bangladesh
}

\author{
Muhammad Abdur Rahim ${ }^{1}$, Palash Mitra ${ }^{1}$, Hasna Fahmima Haque ${ }^{2}$, Tasrina Shamnaz Samdani ${ }^{3}$, \\ Shahana Zaman and Khwaja Nazim Uddin ${ }^{2}$ \\ ${ }^{I}$ Department of Nephrology, Ibrahim Medical College \& BIRDEM General Hospital, Dhaka, Bangladesh; \\ ${ }^{2}$ Department of Internal Medicine, Ibrahim Medical College \& BIRDEM General Hospital, Dhaka, \\ Bangladesh; ${ }^{3}$ Department of Medicine, Delta Medical College and Hospital, Dhaka, Bangladesh; \\ ${ }^{4}$ Department of Cardiology, NICVD, Dhaka, Bangladesh
}

\begin{abstract}
Background and objectives: Diabetes mellitus is one of the most common causes of chronic kidney disease (CKD). The prevalence of CKD in type 2 diabetes mellitus (T2DM) in Bangladesh is not well described. The present study aimed to find out the prevalence of CKD stages 3-5 and its risk factors among selected Bangladeshi T2DM patients.

Methods: This cross-sectional study was conducted in BIRDEM (Bangladesh Institute of Research and Rehabilitation in Diabetes, Endocrine and Metabolic Disorders) General Hospital, Dhaka, Bangladesh from July to December 2015. Diagnosed adult T2DM patients were consecutively and purposively included in this study. Pregnant women, patients with diagnosed kidney disease due to non-diabetic etiology, acute kidney injury (AKI), AKI on CKD and patients on renal replacement therapy were excluded. Age, gender, body mass index (BMI) and laboratory parameters were recorded systematically in a predesigned data sheet. Diagnosis of CKD and its stages were determined according to Kidney Disease: Improving Global Outcomes (KDIGO) Clinical Practice Guidelines 2012 and estimated glomerular filtration rate (eGFR). Estimated GFR was calculated by using Modification of Diet in Renal Disease (MDRD), Cockcroft-Gault (CG) and Chronic Kidney Disease Epidemiology (CKDEPI) creatinine based formula.

Results: A total of 400 patients with T2DM of various durations were enrolled in the study. Out of 400 patients, 254 (63.5\%), $259(64.75 \%)$ and $218(54.5 \%)$ cases had CKD stages 3-5 according to MDRD, C-G and CKD-EPI equations respectively. CKD was significantly more common in females $(p<0.001)$ and in cases with long duration of diabetes $(\geq 5$ years; $\mathrm{p}=0.007)$. CKD stages $3-5$ were significantly associated with hypertension $\left(\chi^{2}=5.2125, p\right.$ $=0.02)$ and good control of diabetes $(\mathrm{HbA} 1 \mathrm{c}<7 \%)$ as evidenced by higher proportion of CKD in them (73.3\%) compared to those with poor glycemic control (52.1\%).

Conclusions: More than half of T2DM patients had CKD stages 3-5. Female gender, duration of diabetes and hypertension were significant risk factors and should be emphasized for the prevention of CKD in T2DM. Glycemic control may not reduce CKD in diabetes.
\end{abstract}

IMC J Med Sci 2017; 11(1): 19-24

\section{Introduction}

Diabetes mellitus (DM) is a global public health problem. The prevalence of DM, particularly type 2
DM (T2DM), is increasing more in low and middleincome countries [1]. DM is now one of the leading causes of chronic kidney disease (CKD) and end-

\section{Address for Correspondence:}

Dr. Muhammad Abdur Rahim, Assistant Professor, Department of Nephrology, Ibrahim Medical College \& BIRDEM

General Hospital. 122 Kazi Nazrul Islam Avenue, Dhaka, Bangladesh.Email: muradrahim23@yahoo.com 
stage renal disease (ESRD) both in developed and developing countries [2-7]. Approximately, $40 \%$ of all diabetic patients develop nephropathy and onethird to half of the patients requiring renal replacement therapy for their ESRD is primarily due to DM [8-11]. Increased longevity, long duration of DM, poor glycemic control, hypertension, dyslipidemia and other diabetic complications are established risk factors for nephropathy and CKD in diabetic patients [12]. The prevalence of nephropathy and CKD in patients with T2DM is $10.8 \%$ to $46 \%$ in different studies, largely depending on screening methods used. However, only limited information is available on prevalence of CKD among Bangladeshi population with T2DM [13]. Therefore, the present study was designed to evaluate the prevalence and potential risk factors of CKD stages 3-5 among Bangladeshi patients withT2DM.

\section{Methods}

This cross-sectional study was conducted at the outpatient department (OPD) of Bangladesh Institute of Research and Rehabilitation in Diabetes, Endocrine and Metabolic Disorders (BIRDEM) General Hospital, Dhaka, Bangladesh from July to December 2015. Diagnosed adult T2DM cases of either sex, irrespective of duration of diabetes were consecutively and purposively included in this study. Pregnant ladies with T2DM, patients with diagnosed kidney disease due to non-diabetic etiology, acute kidney injury (AKI), AKI on CKD and patients with a diagnosis of end stage renal disease (ESRD) on maintenance hemodialysis or continuous ambulatory peritoneal dialysis and renal transplant recipients were excluded from the study. Age, gender, BMI and laboratory parameters were recorded systematically in a predesigned data sheet. Enrolled patients were evaluated clinically for microvascular (retinopathy, nephropathy and neuropathy) and macrovascular (coronary artery disease, cerebrovascular disease including stroke and transient ischemic attack and peripheral vascular disease) complications. Diagnosis of CKD and its stages were determined according to the KDIGO 2012 clinical practice guideline for the evaluation and management of chronic kidney disease [14] using estimated glomerular filtration rate (eGFR). Estimated GFR was calculated by 4-variable Modification of Diet in Renal Disease (MDRD), Cockcroft-Gault (C-G) and the Chronic Kidney Disease Epidemiology (CKD-EPI) creatinine based equations [14-17]. Stage 3 CKD was further sub typed as stage $3 \mathrm{a}\left(\mathrm{eGFR} 45-59 \mathrm{ml} / \mathrm{min} / 1.73 \mathrm{~m}^{2}\right)$ and $3 \mathrm{~b}$ (eGFR $30-44 \mathrm{ml} / \mathrm{min} / 1.73 \mathrm{~m}^{2}$ ) based on eGFR values. Cases diagnosed as CKD stages 3-5 (eGFR 45 to $<15 \mathrm{ml} / \mathrm{min} / 1.73 \mathrm{~m}^{2}$ ) by CKD-EPI formula was only considered for determining the association between different variables. The qualitative data were presented in percentages and quantitative in mean with standard deviation (SD). $\chi^{2}$-test was used to determine the association between variables.

\section{Results}

A total of $400 \mathrm{~T} 2 \mathrm{DM}$ patients were enrolled of which 169 and 231 were males and females respectively. The mean age of the study population was $54.9 \pm 10.5$ years and the mean duration of diabetes from detection was $11.6 \pm 7.6$ years. The mean HbA1c was $9.1 \pm 2.0 \%$ indicating poor glycemic control (Table-1). Diabetes related chronic complications of the study population are presented in Table-2.

Table-1: Baseline characteristics of the study population $(n=400)$

\begin{tabular}{lc}
\hline Characteristics & Value \\
\hline Mean age (yrs) & $54.9 \pm 10.5$ \\
Male: female ratio & $1: 1.4$ \\
Rural: urban ratio & $1: 3.1$ \\
Mean duration of diabetes (yrs) & $11.6 \pm 7.6$ \\
Mean BMl (Kg/m²) & $24.6 \pm 4.5$ \\
Mean HbA1c (\%) & $9.1 \pm 2.0$ \\
\hline
\end{tabular}

Note: $B M I=$ body mass index, HbAlc= glycated hemoglobin

Table-2: Microvascular and macrovascular complications among the study population $(n=400)$

\begin{tabular}{lc}
\hline Complications & Number (\%) \\
\hline Microvascular & $119(29.8)$ \\
Neuropathy & $151(37.8)$ \\
Retinopathy & $218(54.5)$ \\
*Nephropathy/CKD stages 3-5 & \\
Macrovascular & $103(25.8)$ \\
$\quad$ Coronary artery disease & $44(11.0)$ \\
Stroke/TIA & $56(14.0)$ \\
Peripheral vascular disease & \\
\hline
\end{tabular}

Note: ${ }^{*} C K D$ stages 3-5 as per CKD-EPI formula [14]; $T I A=$ transient ischemic attack 
Out of 400 enrolled cases, $29.8 \%, 37.8 \%$ and $54.5 \%$ had neuropathy, retinopathy and CKD respectively. Macrovascular complications were present in $11.0 \%$ to $25.8 \%$ cases. Out of 400 cases, $254(63.5 \%), 259(64.75 \%)$ and 218 (54.5\%) cases had CKD stages 3-5 according to MDRD, C-G and CKD-EPI methods respectively. Detail results of CKD stages 3-5 by MDRD, C-G and CKD-EPI methods are shown in Table-3.

Table-3: Frequency of different stages of CKD according to different equations among the study population $(n=400)$

\begin{tabular}{lccc}
\hline \multicolumn{1}{c}{ CKD stages } & $\begin{array}{c}\text { MDRD } \\
\mathbf{n}(\%)\end{array}$ & $\begin{array}{c}\text { C-G } \\
\mathbf{n}(\%)\end{array}$ & $\begin{array}{c}\text { CKD-EPI } \\
\mathbf{n}(\%)\end{array}$ \\
\hline $\begin{array}{l}\text { Stage 3a } \\
\text { [GFR 45-59] }\end{array}$ & $111(27.8 \%)$ & $87(21.8 \%)$ & $101(25.3 \%)$ \\
Stage 3b & $77(19.3 \%)$ & $106(26.5 \%)$ & $54(13.5 \%)$ \\
[GFR 30-44] & & & \\
Stage 4 & $45(11.3 \%)$ & $51(12.8 \%)$ & $42(10.5 \%)$ \\
[GFR 15-29] & & & \\
Stage 5 & $21(5.3 \%)$ & $15(3.8 \%)$ & $21(5.3 \%)$ \\
[GFR <15] & & & \\
\hline
\end{tabular}

Note: GFR was measured in $\mathrm{ml} / \mathrm{min} / 1.73 \mathrm{~m}^{2}$.

Cases of CKD stages 3-5 diagnosed by CKD-EPI formula was considered to find out the association of CKD stages 3-5 with different variables namely gender, family history of diabetes, duration of diabetes, hypertension, BMI, dyslipidemia and HbA1c status. In our study, CKD stages 3-5 was associated in significantly $\left(\chi^{2}=18.4, p \leq 0.001\right)$ higher proportion in females compared to males $(63.6 \%$ vs. $42 \%)$ and in patients with diabetes of more than 5 years duration (59.6\%) compared to those of less than 5 years $\left(30.0 \% ; \chi^{2}=19.25\right.$, $\mathrm{p} \leq .001$ ). CKD stages 3-5 were present in $57.2 \%$ cases having pre-existing or concomitant hypertension while it was $42.7 \%$ among those who had no hypertension. It was interesting to note that CKD stages 3-5 were present in higher number of cases (73.3\%) having good glycemic control (HbAlc $<7 \%$ ) compared to those who had poor glycemic control (HbAlc $\geq 7 \%)$. On the other hand, there was no significant association of CKD with family history of diabetes, dyslipidemia and BMI (Table-4).
Table-4: Presence of CKD stages 3-5 in relation to different risk factors

\begin{tabular}{llccc}
\hline \multicolumn{1}{c}{ Risk factors } & $\begin{array}{c}\text { Total } \\
\text { Number }\end{array}$ & $\begin{array}{c}\text { * Presence } \\
\text { of CKD } \\
\text { stages 3-5 } \\
\mathbf{n}(\%)\end{array}$ & $\begin{array}{c}\boldsymbol{p} \\
\text { value }\end{array}$ \\
\hline Sex & Male & 169 & $71(42.0)$ & 0.001 \\
& Female & 231 & $147(63.6)$ & \\
Family & Present & 204 & $110(53.9)$ & 0.810 \\
history of DM & Absent & 196 & $108(55.1)$ & \\
Duration of & $\geq 5$ years & 329 & $196(59.6)$ & 0.001 \\
DM & $<5$ years & 71 & $22(30.0)$ & \\
Hypertension & Present & 325 & $186(57.2)$ & 0.022 \\
& Absent & 75 & $32(42.7)$ & \\
Dyslipidemia & Present & 151 & $84(55.6)$ & 0.726 \\
& Absent & 249 & $134(53.8)$ & \\
BMI & $\geq 25 \mathrm{~kg} / \mathrm{m}^{2}$ & 161 & $94(58.4)$ & 0.200 \\
& $<25 \mathrm{~kg} / \mathrm{m}^{2}$ & 239 & $124(51.9)$ & \\
HbA1c & $\geq 7 \%$ & 355 & $185(52.1)$ & 0.007 \\
\hline
\end{tabular}

Note: *As per CKD-EPI method; Total case of CKD stages $3-5=218 ; \chi^{2}$ test was used to determine the association.

\section{Discussion}

$\mathrm{DM}$ is one of the most common causes of CKD. Most patients with CKD remain asymptomatic in early stages. Therefore, in the current study we have tried to evaluate clinically significant CKD stages 3-5 among T2DM patients. CKD implies considerable morbidity, mortality and health-care related costs [18]. Diagnosis of CKD in diabetic patients warrants significant changes in management of patients, both for DM and other cardiovascular risk factors. Many CKD patients die of cardiovascular events before reaching ESRD [19]. Worth mentioning that, early stages of diabetic nephropathy also increase cardiovascular risks by many folds [20].

The results of the present study showed that over half of the patients $(54.5 \%$ to $64.8 \%)$ with T2DM had CKD stages 3-5 irrespective of methods/ formulas used for estimation of eGFR. Depending on different equations used, the overall rates of CKD stages 3-5 were almost similar by three different methods. Studies from UK, USA, Spain and Australia have reported the prevalence of CKD in T2DM patients as $27.5 \%$ (stage 3-5), $43.5 \%$, $27.9 \%$ and $47.1 \%$ respectively $[21,2,22,23]$. The 
rate is almost similar (23.8 to $46.0 \%)$ in developing countries $[7,12,24,25]$. The wide variation of prevalence of CKD among the T2DM cases in different studies may reflect quality of diabetes care, screening methods used and stages of CKD included in these studies.

In the present study, we have used the number of patients diagnosed as having CKD stages 3-5 by CKD-EPI method for assessing its relation with different factors. We have found that CKD was significantly more common in females, in patients with hypertension and in those with long duration of diabetes. These are well recognized risk factors for CKD in diabetes and have been reported in several studies done in developed as well as developing countries of the world [7,12,23,25]. It was interesting to note that CKD was present in significantly higher proportion in those who had adequate glycemic control (HbA1c <7\%). But this finding is not unusual. Recent investigations contradict the previous thought that the strict glycemic control prevents microvascular diabetic complications [26]. Some observed that microvascular complications could not be altered by near-normalization of glucose [27]. Previous study in Bangladesh observed significantly higher microvascular complications in cases with strict glycemic control compared to those with inadequate glycemic control [28]. It may be possible that strict glycemic control may have injurious effects on kidney due to sustained low blood sugar level.

Current study had some potential limitations. It was a single center study, done in a tertiary care hospital with relatively small number of patients with T2DM. It might not be generalized for Bangladeshi T2DM subjects. Moreover, we did not estimate urine for albumin to creatinine ratio (UACR) or 24$\mathrm{h}$ urinary total protein, by which a good number of patients with early diabetic nephropathy/CKD could be identified. We only relied on eGFR. Further study including multiple centers, large number of study participants and evaluation of all stages of diabetic nephropathy/CKD would provide a more representative picture in this regard from Bangladesh.

In conclusion, it can be said that, CKD stages 3-5 were present in more than $50 \%$ of patients with T2DM in this study and the prevalence was significantly higher in patients with hypertension and long duration of diabetes. Strict glycemic control may not prevent or reduce CKD in diabetes. Optimum control of hypertension may prevent the development of CKD and its progress in patients with T2DM. Physicians, especially those, who serve the diabetic patients at all levels starting from the primary care setting, should be aware of the possible risk factors of complications and should educate the patients about those potential factors.

\section{Acknowledgement}

We express our acknowledgement to all our colleagues who helped us to collect data from the study participants.

Conflict of interest: None declared.

\section{References}

1. Wild S, Roglic G, Green A, Sicree R, King H. Global prevalence of diabetes: estimates for the year 2000 and projections for 2030. Diabetes Care. 2004; 27: 1047-53.

2. Bailey RA, Wang Y, Zhu V, Rupnow MFT. Chronic kidney disease in US adults with type 2 diabetes: an updated national estimate of prevalence based on Kidney Disease: Improving Global Outcomes (KDIGO) staging. BMC Res Notes. 2014; 7: 415.

3. The UK Renal Registry. The Sixth Annual Report 2003.

4. ANZ Data Registry. The twenty-sixth report. Adelaide: Australia and New Zealand Dialysis and Transplant registry. 2003.

5. Singh AK, Farag YMK, Mittal BV, Subramanian KK, Reddy SRK, Acharya VN et al. Epidemiology and risk factors of chronic kidney disease in India - results from the SEEK (Screening and Early Evaluation of Kidney Disease) study. BMC Nephrology. 2013; 14: 114.

6. Ahmed ST, Rahim MA, Ali MZ, Iqbal MM. Prevalence of primary renal diseases among patients on maintenance haemodialysis: a hospital based study. KYAMC Journal. 2012; 2(2): 182-86. 
7. Fiseha T, Kassim M, Yemane T. Prevalence of chronic kidney disease and associated risk factors among diabetic patients in southern Ethiopia. Am J Health Res. 2014; 2(4): 216-21.

8. Remuzzi G, Schieppati A, Ruggenenti P. Clinical practice. Nephropathy in patients with type 2 diabetes. $N$ Engl $J$ Med. 2002; 346: 1145-51.

9. Ritz E, Rychlik I, Locatelli F, Halimi S. Endstage renal failure in type 2 diabetes: a medical catastrophe of worldwide dimensions. Am J Kidney Dis. 1999; 34: 795-808.

10. USRDS: The United States Renal Data System. Experts from the USRDS 2009 annual data report: atlas of end-stage renal disease in the United States. Am J Kidney Dis. 2010; 55(suppl. 1): S1.

11. Atkins RC. The epidemiology of chronic kidney disease. Kidney Int 2005; 67: 14-18.

12. Al-Rubeaan K, Youssef AM, Subhani SN, Ahmad NA, Al-Sharqawi AH, Al-Mutlaq HM et al. Diabetic nephropathy and its risk factors in a society with a type 2 diabetes epidemic: a Saudi National Diabetes Registry-based study. PLoS ONE. 2014; 9(2): e88956. doi:10.1371/ journal. pone.0088956

13. Latif ZA, Jain A, Rahman MM. Evaluation of management, control, complications and psychosocial aspects of diabetics in Bangladesh: DiabCare Bangladesh 2008. Bangladesh Med Res Counc Bull. 2011; 37(1): 11-16.

14. Kidney Disease: Improving Global Outcomes (KDIGO) CKD Work Group. KDIGO 2012 Clinical Practice Guideline for the Evaluation and Management of Chronic Kidney Disease. Kidney Int. (Suppl.) 2013; 3: 1-150.

15. Levey AS, Greene T, Kusek JW, Beck GL, MDRD Study Group. A simplified equation to predict glomerular filtration rate from serum creatinine (abstract). J Am Soc Nephrol. 2000; 11: $155 \mathrm{~A}$.

16. Cockcroft DW, Gault MH. Prediction of creatinine clearance from serum creatinine. Nephron.1976; 16(1):31-41.

17. Levey AS, Stevens LA, Schmid CH, Zhang YL, Castro III AF, Feldman HI, et al. CKD-
EPI (Chronic Kidney Disease Epidemiology Collaboration). A new equation to estimate glomerular filtration rate. Ann Intern Med. 2009; 150(9): 604-12.

18. Afkarian M, Sachs MC, Kestenbaun B, Hirsch IB, Tuttle KR, Himmelfarb J et al. Kidney disease and increased mortality risk in type 2 diabetes. J Am Soc Nephrol. 2013; 24: 302-308.

19. Collins AJ1, Li S, Gilbertson DT, Liu J, Chen SC, Herzog CA. Chronic kidney disease and cardiovascular disease in the Medicare population. Kidney Int Suppl. 2003; 87:S24-31.

20. Daly C. Is early chronic kidney disease an important risk factor for cardiovascular disease? A background paper prepared for the UK Consensus Conference on early chronic kidney disease. Nephrol Dial Transplant. 2007; 22 (Suppl. 9): 19-25.

21. Middelton RJ, Foley RN, Hegarty J, Cheung CM, McElduff P, Ginson JM et al. The unrecognized prevalence of chronic kidney disease in diabetes. Nephrol Dial Transplant. 2006; 21: 88-92.

22. Prevalence of chronic kidney disease in patients with type 2 diabetes in Spain: PERCEDIME2 study. BMC Nephrology. 2013; 14: 46 .

23. Thomas MC, Weekes AJ, Broadley OJ, Cooper ME, Mathew TH. The burden of chronic kidney disease in Australian patients with type 2 diabetes (the NEPHRON study). Med J Aust. 2006; 185(3): 140-44.

24. Prasannakumar M, Rajput R, Seshadri K, Talwalkar P, Agarwal P, Gokulnath G et al. An observational, cross-sectional study to assess the prevalence of chronic kidney disease in type 2 diabetes patients in India (STARTIndia). Indian $J$ Endocr Metab. 2015; 19: 520-23.

25. Low SKM, Sum CF, Yeoh LY, Tavintharan $\mathrm{S}, \mathrm{Ng} \mathrm{XW}$, Lee SBM et al. Prevalence of chronic kidney disease in adults with type 2 diabetes mellitus. Ann Acad Med Singapore. 2015; 44: 164-71.

26. Ismail-Beigi F, Craven TE, O'Connor PJ, Diane Karl, Calles-Escandon J, Hramiak I, et 
24 IMC J Med Sci 2017; 11(1): 19-24

Rahim MA et al.

al. for the ACCORD Study Group. Combined intensive blood pressure and glycemic control does not produce an additive benefit on microvascular outcomes in type 2 diabetic patients. Kidney Int. 2012; 81(6): 586-594.

27. O'Connor PJ, Ismail-Beigi F. Near-normalization of glucose and microvascular diabetes complications: data from ACCORD and ADVANCE. Ther Adv Endocrinol Metab. 2011; 2(1): 17-26. doi: 10.1177/2042018810390545.

28. Sayeed MA. Predictors of risk for vascular complications and their probability in the diabetic population of Bangladesh [PhD Thesis]. University of Dhaka 2002; 45- 47. 